\title{
Foreword to Sixth Special Issue on Electroporation-Based Technologies and Treatments
}

\author{
P. Thomas Vernier ${ }^{1} \cdot$ Lluis M. Mir $^{2} \cdot$ Damijan Miklavčič $^{3}$
}

Published online: 6 September 2016

(c) Springer Science+Business Media New York 2016

This sixth special issue of the Journal of Membrane Biology on electroporation and electroporation-based technologies and treatments is in several ways a very special special issue.

First, it will be presented to the participants of the 10th Electroporation-Based Technologies and Treatment Postgraduate Course and Scientific Workshop, organized every November in Ljubljana, Slovenia (http://www.ebtt.org). Convening the tenth edition of this unique school will be a milestone for the founding faculty members and for those who have joined in subsequent years, and for all of the alumni of this now-annual gathering, including those who have become Ambassadors of the EBTT.

Second, this special issue contains contributions not only from last year's workshop (68 participants from 19 countries) but also from the 1st World Congress on Electroporation and Pulsed Electric Fields, held in September 2015 in Portorož, Slovenia (https://wc2015.electroporation. net/), where 400 attendees from 42 countries came together and shared their research. Set in a wonderful location, this world congress highlighted for the first time in a single meeting the importance of electroporation not only in biology and medicine but also in the food and environment industries. Everyone working in these fields will want to

P. Thomas Vernier

pvernier@odu.edu

1 Frank Reidy Research Center for Bioelectrics, Old Dominion University, Norfolk, VA, USA

2 Vectorology and Anticancer Therapeutics, UMR 8203 CNRS, Univ. Paris-Sud, Gustave-Roussy, Université Paris-Saclay, Villejuif, France

3 Faculty of Electrical Engineering, University of Ljubljana, Ljubljana, Slovenia mark their calendar for the 2nd World Congress, which will convene in September 2017 in Norfolk, Virginia, USA, under the auspices of the ISEBTT, the new International Society for Electroporation-Based Technologies and Treatments.

Finally, this special issue is the first in collaboration with the new editor-in-chief of the Journal, Prof. Dr. Wolfgang E. Trommer, and we hope that many more will follow. We take this opportunity to express our great appreciation to the former editor-in-chief Professor Thomas B. Woolf for his support in organizing the first special electroporation issue of the journal several years ago. An informal discussion at a poster at the Biophysical Society meeting in 2010 led to an agreement to invite submissions of manuscripts from the EBTT meeting in Ljubljana that year, and with Prof. Woolf's ongoing support the special electroporation issue has become a successful tradition.

In response to last year's call for manuscripts from participants of both the Electroporation-Based Technologies and Treatments School and the 1st World Congress on Electroporation, we received 24 manuscripts, of which finally 20 were accepted and are featured in this special issue. These peer-reviewed papers provide a cross-section of the ongoing electroporation-related research being carried out by participants at the Ljubljana meeting and attendees at the 1st World Congress. We are grateful to the contributors for presenting their recent results, and we are especially grateful to our scientific colleagues who reviewed the manuscripts.

Last and certainly not least, we acknowledge the support of the agencies, societies, and companies who support the school, in particular the Slovenian Research Agency, the Centre National de la Recherche Scientifique (CNRS), and the Bioelectrochemical Society, which have sponsored the school from its very beginning, and also IGEA (Italy), 
Mediline (Slovenia), Iskra Medical (Slovenia), BIA Separations (Slovenia), LTFE (Slovenia), and LEROY Biotech (France), who made it possible to increase student participation through reduced fees and lodging expenses. The workshop and postgraduate course was conducted within the scope and with the support of the European Associated Laboratory on Pulsed Electric Fields Applications in Biology and Medicine (LEA EBAM) and co-organized by COST TD1104 Action (http://www.electroporation.net/). 